\title{
SNM Practice Guideline for Hepatobiliary Scintigraphy $4.0^{*}$
}

Mark Tulchinsky ${ }^{1}$, Brian W. Ciak $^{2}$, Dominique Delbeke ${ }^{3}$, Andrew Hilson ${ }^{4}$, Kelly Anne Holes-Lewis ${ }^{5}$, Michael G. Stabin 6 , and Harvey A. Ziessman ${ }^{7}$

${ }^{I}$ PennState Milton S. Hershey Medical Center, Hershey, Pennsylvania; ${ }^{2}$ Bracco Diagnostics, Inc., Princeton, New Jersey; ${ }^{3}$ Vanderbilt University Medical Center, Nashville, Tennessee; ${ }^{4}$ Royal Free Hospital, London, England; ${ }^{5}$ Medical University of South Carolina, Charleston, South Carolina; ${ }^{6}$ Vanderbilt University, Nashville, Tennessee; and ${ }^{7}$ Johns Hopkins Outpatient Center, Baltimore, Maryland

VOICE Credit: This activity has been approved for 1.0 VOICE (Category A) credit. For CE credit, participants can access this activity on page $15 \mathrm{~A}$ or on the SNM Web site (http://www.snm.org/ce_online) through December 31, 2012. You must answer $80 \%$ of the questions correctly to receive $1.0 \mathrm{CEH}$ (Continuing Education Hour) credit.

\section{PREAMBLE}

The Society of Nuclear Medicine (SNM) is an international scientific and professional organization founded in 1954 to promote the science, technology, and practical application of nuclear medicine. Its 16,000 members are physicians, technologists, and scientists specializing in the research and practice of nuclear medicine. In addition to publishing journals, newsletters, and books, the SNM also sponsors international meetings and workshops designed to increase the competencies of nuclear medicine practitioners and to promote new advances in the science of nuclear medicine.

The SNM will periodically define new guidelines for nuclear medicine practice to help advance the science of nuclear medicine and to improve the quality of service to patients throughout the United States. Existing Practice Guidelines will be reviewed for revision or renewal, as appropriate, on their fifth anniversary or sooner, if indicated.

Each Practice Guideline, representing a policy statement by the SNM, has undergone a thorough consensus process in which it has been subjected to extensive review, requiring the approval of the Committee on SNM Guidelines, Health Policy and Practice Commission, and SNM Board of Directors. The Practice Guidelines recognize that the safe and effective use of diagnostic nuclear medicine imaging requires specific training, skills, and techniques, as described in each document. Reproduction or modification

\footnotetext{
Received Aug. 13, 2010; revision accepted Aug. 23, 2010.

For correspondence or reprints contact: Dominique Delbeke, Vanderbilt University Medical Center, 21st Ave. S. and Garland, Nashville, TN 372322675.

E-mail: dominique.delbeke@vanderbilt.edu

*NOTE: YOU CAN ACCESS THIS GUIDELINE THROUGH THE SNM WEB SITE (http://www.snm.org/guidelines). FOR CE CREDIT, YOU CAN ACCESS THIS ACTIVITY AT (http://www.snm.org/ce_online) THROUGH DECEMBER 2012.

COPYRIGHT (C) 2010 by the Society of Nuclear Medicine, Inc. DOI: $10.2967 /$ jnmt.110.082289
}

of the published Practice Guideline by those entities not providing these services is not authorized.

These Practice Guidelines are an educational tool designed to assist practitioners in providing appropriate care for patients. They are not inflexible rules or requirements of practice and are not intended, nor should they be used, to establish a legal standard of care. For these reasons and those set forth below, the SNM cautions against the use of these Practice Guidelines in litigation in which the clinical decisions of a practitioner are called into question.

The ultimate judgment regarding the propriety of any specific procedure or course of action must be made by the physician or medical physicist in light of all the circumstances presented. Thus, an approach that differs from the Practice Guidelines, standing alone, is not necessarily below the standard of care. To the contrary, a conscientious practitioner may responsibly adopt a course of action different from that set forth in the Practice Guidelines when, in the reasonable judgment of the practitioner, such course of action is indicated by the condition of the patient, limitations of available resources, or advances in knowledge or technology subsequent to publication of the Practice Guidelines.

The practice of medicine involves not only the science, but also the art, of preventing, diagnosing, alleviating, and treating disease. The variety and complexity of human conditions make it impossible to always reach the most appropriate diagnosis or to predict with certainty a particular response to treatment. Therefore, it should be recognized that adherence to these Practice Guidelines will not ensure an accurate diagnosis or a successful outcome. All that should be expected is that the practitioner will follow a reasonable course of action based on current knowledge, available resources, and the needs of the patient to deliver effective and safe medical care. The sole purpose of these Practice Guidelines is to assist practitioners in achieving this objective. 


\section{INTRODUCTION}

This Practice Guideline has been developed and revised collaboratively by the SNM Task Force with input from the American College of Radiology and the European Association of Nuclear Medicine. The Task Force assembled by the SNM included representatives from the other 2 organizations.

Optimally performed hepatobiliary scintigraphy is a sensitive method for detecting numerous disorders involving the liver and biliary system. It is generally accepted that scintigraphic findings are not always specific. Therefore, it is crucial to correlate findings on hepatobiliary scintigraphy with clinical information and findings on other relevant modalities in order to arrive at a correct diagnosis. Adjunctive pharmacologic maneuvers may enhance the diagnostic utility of hepatobiliary scintigraphy and provide the quantitative assessment necessary for certain specific applications.

\section{GOALS}

The purpose of this Practice Guideline is to assist nuclear medicine practitioners in recommending, performing, interpreting, and reporting the results of hepatobiliary scintigraphy in adults and children.

The goal of hepatobiliary scintigraphy is to provide diagnostic and management assistance to physicians who are involved in the care of patients with liver and biliary system ailments.

\section{DEFINITIONS}

Hepatobiliary scintigraphy is a radionuclide diagnostic imaging study (including planar imaging, SPECT, or hybrid imaging such as SPECT/CT) that evaluates hepatocellular function and the biliary system by tracing the production and flow of bile from the formative phase in the liver, and its passage through the biliary system into the small intestine. Sequential (or dynamic) images of the liver, biliary tree, and gut are obtained. Computer acquisition and analysis, including pharmacologic interventions, are used according to varying indications and an individual patient's needs.

\section{COMMON CLINICAL INDICATIONS}

\section{A. Indications}

1. Functional biliary pain syndromes in adults $(1-11)$

2. Functional biliary pain syndromes in pediatric patients (12-17)

3. Acute cholecystitis $(11,18-30)$

4. Right-upper-quadrant pain variants, as defined by the American College of Radiology Appropriateness Criteria (31)

5. Biliary system patency $(11,32-35)$

6. Bile leakage $(11,36-40)$

7. Neonatal hyperbilirubinemia (biliary atresia vs. neonatal hepatitis "syndrome") (11,41-43)

8. Assessment of biliary enteric bypass (e.g., Kasai procedure) $(11,44,45)$
9. Assessment of liver transplant (11,46-51)

10. Afferent loop syndrome (52-56)

11. Assessment of choledochal cysts (11,57-64)

12. Calculation of gallbladder ejection fraction (GBEF) (11)

13. Functional assessment of the liver before partial hepatectomy $(65,66)$

14. Demonstration of anomalous liver lobulation (67)

15. Enterogastric (duodenogastric) reflux assessment (68-71)

16. Esophageal bile reflux after gastrectomy (72)

17. Sphincter of Oddi dysfunction (73-77)

B. Contraindications

1. Hypersensitivity to a hepatobiliary compound (78)

C. Warnings

1. For pregnant or potentially pregnant patients see the SNM Procedure Guideline for General Imaging.

2. A theoretic possibility of allergic reactions should be considered in patients who receive multiple doses of hepatobiliary compound (78).

\section{QUALIFICATIONS AND RESPONSIBILITIES OF PERSONNEL}

See Section V of the SNM Procedure Guideline for General Imaging.

\section{THE PROCEDURE/SPECIFICATION OF THE EXAMINATION}

A. Request

The nuclear medicine physician should review all available pertinent clinical, laboratory, and radiologic information before the study. Additional information specifically related to hepatobiliary scintigraphy includes:

1. History of previous surgeries, especially biliary and gastrointestinal

2. Time of most recent meal

3. Current medications, including the time of their most recent administration (with particular attention to opioid compounds)

4. Results of bilirubin and liver enzyme levels

5. Results of gallbladder or abdominal ultrasound

B. Patient preparation and precautions

To permit timely gallbladder visualization, the adult patient must have fasted for a minimum of 2 and preferably $6 \mathrm{~h}$ before administration of the radiopharmaceutical. Children should be instructed to fast for 2-4 h, whereas infants need to fast for only $2 \mathrm{~h}$ before radiotracer injection. In the latter group, clear liquids are permissible, if medically necessary.

However, fasting for longer than $24 \mathrm{~h}$ (including those on total parenteral nutrition), can cause the gallbladder not to fill with radiotracer within the normally expected time frame. In these cases the patient may be pretreated with sincalide, as described in VI.E.1 below. Disregard of the above guidelines may result in a false-positive nonvisualization of the gallbladder. 
Interference by opioids can be minimized by delaying the study for a time corresponding to 4 half-lives of a medication. In some cases the effect can be reversed with naloxone hydrochloride. Additional details are listed in VI.G.

\section{Radiopharmaceutical}

99mTc-disofenin (2,6-diisopropylacetanilido iminodiacetic acid) or ${ }^{99 \mathrm{~m}} \mathrm{Tc}$-mebrofenin (bromo-2,4,6-trimethylacetanilido iminodiacetic acid) is administered intravenously in activities of 111-185 MBq (3-5 mCi) for adults; a higher administered activity may be needed in hyperbilirubinemia. Mebrofenin may be selected instead of disofenin in moderate to severe hepatic dysfunction because of its higher hepatic extraction.

The administered activity for infants and children is 1.8 $\mathrm{MBq} / \mathrm{kg}(0.05 \mathrm{mCi} / \mathrm{kg})$, with a minimum administered activity of $18.5 \mathrm{MBq}(0.5 \mathrm{mCi})$ (79). Mebrofenin is always preferred in neonates with hyperbilirubinemia, with a minimum administered activity of $37 \mathrm{MBq}(1.0 \mathrm{mCi})$, as up to 24-h delayed images are often necessary.

D. Protocol/image acquisition

1. Image acquisition

A large-field-of-view $\gamma$-camera equipped with a lowenergy all-purpose or high-resolution collimator is recommended. Whenever possible, continuous (dynamic) computer acquisition (usually in the anterior or left anterior oblique view) should be performed (1 frame/min). The image matrix of 128 by 128 is optimal on a standard large-field-of-view camera. In pediatric patients an appropriate electronic acquisition zoom should be used. Initial images are usually acquired dynamically, starting at injection and continuing for $60 \mathrm{~min}$. When visualization of the gallbladder is the endpoint of the study, it can be stopped earlier when activity is seen in the gallbladder. Additional views (e.g., right lateral, left or right anterior oblique) may be obtained as needed to clarify anatomy. To resolve concern about common bile duct obstruction (highly unlikely in the presence of gallbladder visualization), demonstration of tracer activity in the small bowel may need to be pursued.

The digital data can be reformatted to 4- to 6-min images for filming or digital display. Cinematic display of the data may reveal additional information not readily apparent on reformatted display. Image intensity scaling should be study-relative rather than individual frame-relative. The former allows for appreciation of activity changes over the duration of the study.

When acute cholecystitis is suspected and the gallbladder is not seen within $60 \mathrm{~min}$, delayed images for up to 3-4 h should be obtained, or morphine augmentation (VI.E.2) may be used in lieu of delayed imaging. Delayed imaging at 18-24 h may be necessary in some cases (e.g., a severely ill patient, severe hepatocellular dysfunction, suspected common bile duct obstruction, or suspected biliary atresia).

If the patient is being studied for a biliary leak, 2- to 4-h delayed imaging (or longer delays in some cases) and patient-positioning maneuvers (e.g., decubitus views) may be helpful. Any drainage bags should by included in the field of view if the biliary origin of a leak or fistula is in question. In patients with a suspected leak, it may be helpful to acquire simultaneous right lateral or other views on a multihead camera.

2. Processing

a. For GBEF, using the immediate presincalide and the postsincalide images, regions of interest (ROI) are drawn around the gallbladder (taking into account patient motion) and adjacent liver (background) using any standard nuclear medicine software package. The liver background ROI is selected taking care to exclude ductal activity. GBEF is calculated from the gallbladder time-activity curve as:

$$
\operatorname{GBEF}(\%)=\frac{\left(\text { net GB }_{\max }\right)-\left(\text { net GB }_{\text {min }}\right) \times 100}{\text { net } \mathrm{GB}_{\max }},
$$

where GB is gallbladder counts.

b. Hepatocellular function may be assessed by deconvolution analysis from an ROI over the liver and heart (hepatic extraction fraction) or by analysis of a heart ROI for tracer clearance from the blood pool $(80,81)$.

\section{E. Interventions}

A variety of pharmacologic or physiologic interventions may enhance the diagnostic value of the examination. Appropriate precautions should be taken to promptly detect and treat any adverse reactions caused by these interventions. It is important to be familiar with all contraindications and warnings detailed in package inserts of the pharmaceuticals listed below.

1. Sincalide pretreatment

Sincalide, a synthetic C-terminal octapeptide of cholecystokinin, may be given intravenously in doses of 0.02 $\mu \mathrm{g} / \mathrm{kg}$ over 30-60 min, 15-30 min before the hepatobiliary tracer injection, to minimize the potential for a false-positive study (e.g., in patients who have fasted longer than $24 \mathrm{~h}$, are on parenteral hyperalimentation, or have a severe intercurrent illness) (82-85).

In patients suspected of sphincter of Oddi dysfunction because of persistent abdominal colic after cholecystectomy, sincalide-pretreatment cholescintigraphy can be used as a diagnostic screening test (73). Sincalide $(0.02 \mu \mathrm{g} / \mathrm{kg})$ is administered intravenously over $3 \mathrm{~min}$, and the imaging starts 15 min later in anterior projection and is continued for $60 \mathrm{~min}$. ROIs are placed over the liver parenchyma and the common bile duct to generate the time-activity curves. The interpretation criteria are based on the scoring system designed by the test developers (73).

2. Morphine sulfate

When acute cholecystitis is suspected and the gallbladder is not seen by $30-60 \mathrm{~min}$, morphine sulfate, $0.04 \mathrm{mg} / \mathrm{kg}$ or a standard $2 \mathrm{mg}$ dose, may be administered intravenously over $2-3 \mathrm{~min}(25,28)$. If the cystic duct is patent, flow of bile into the gallbladder will be facilitated by morphineinduced temporary spasm of the sphincter of Oddi. The 
intrahepatic biliary tree and common bile duct must contain radioactive bile, and the tracer activity should be present in the small bowel at the time of morphine injection. A second injection of radiopharmaceutical, $74 \mathrm{MBq}(2 \mathrm{mCi})$, may be necessary before morphine administration if the remaining liver or biliary tree activity appears insufficient to permit gallbladder filling, or the second injection can be given as a standard part of the test (25). Imaging is continued for another 30-60 min after morphine administration. This time should be extended if there is poor hepatocyte function. Contraindications to the use of morphine include increased intracranial pressure in children (absolute), respiratory depression in nonventilated patients (absolute), morphine allergy (absolute), and acute pancreatitis (relative).

3. Sincalide stimulation

Gallbladder contractility may be evaluated by determining GBEF after sincalide stimulation. The study involves an intravenous administration of sincalide, and multiple methodologies exist. Knowledge of validated GBEF in healthy people is essential in determining which patient is exhibiting an abnormal result. Table 1 summarizes the expected GBEF for tested techniques.

The best-validated reference dataset with the greatest number of healthy volunteers points to an infusion of $0.02 \mu \mathrm{g} / \mathrm{kg}$ over $60 \mathrm{~min}$ as one that can result in least variability of reference values (85) and may be considered the method of choice. The reference GBEF with this methodology should be $\geq 38 \%$. The effectiveness of this method in chronic gallbladder disease has not been reported to date.

A dataset with infusion of $0.15 \mu \mathrm{g} / \mathrm{kg}$ over $45 \mathrm{~min}$ and GBEF measured at $60 \mathrm{~min}$ showed acceptable variability (3). For this method, authors suggest GBEF $\geq 40 \%$ as normal. This methodology is the only one that has a prospective, randomized study that supports its use in patients with chronic acalculous gallbladder disease.
Of concern was that shorter infusions showed a number of healthy subjects with very low GBEFs that would be commonly reported as pathologic $(2,85)$, raising a falsepositive test result.

4. GBEF measurement using a fatty meal challenge instead of sincalide has also been described $(89,90)$. This approach is not as reproducible in healthy subjects (has greater variability) as is the sincalide methodology suggested in the preceding section.

5. In jaundiced infants in whom biliary atresia is suspected, pretreatment with phenobarbital, $5 \mathrm{mg} / \mathrm{kg} / \mathrm{d}$, may be given orally in 2 divided doses daily for a minimum of 3-5 d before the hepatobiliary imaging study to enhance biliary excretion of the radiotracer and increase the specificity of the test (41). Mebrofenin may be preferred over disofenin in suspected biliary atresia because the former has better hepatic excretion than the latter, especially in these patients with hepatocellular dysfunction.

6. In jaundiced infants in whom biliary atresia is suspected, pretreatment with ursodeoxycholic acid is an alternative (43). The dose is $20 \mathrm{mg} / \mathrm{kg} / \mathrm{d}$ in 2 divided doses (12 $\mathrm{h}$ apart) for 2-3 $\mathrm{d}$ before the scan. This medication is continued until the test is over. In comparison to phenobarbital, ursodeoxycholic acid does not cause sedation in infants and may be an advantage in certain patients. Another advantage to consider is shorter premedication. As with phenobarbital, mebrofenin is favored over disofenin.

\section{F. Interpretation}

1. Normal hepatobiliary findings are characterized by the immediate demonstration of hepatic parenchyma and rapid clearance of cardiac blood-pool activity, followed sequentially by activity in the intra- and extrahepatic biliary ductal system, gallbladder, and upper small bowel. All these structures should be seen within $1 \mathrm{~h}$. Gallbladder filling implies a patent cystic

TABLE 1

Expected GBEF for Tested Techniques

\begin{tabular}{|c|c|c|c|c|c|}
\hline $\begin{array}{l}\text { Sincalide dose } \\
(\mu \mathrm{g} / \mathrm{kg})\end{array}$ & $\begin{array}{c}\text { Time of } \\
\text { infusion (min) }\end{array}$ & $\begin{array}{c}\text { Mean } \\
\text { GBEF } \pm \text { SD }(\%)\end{array}$ & $\begin{array}{c}\text { GBEF } \\
\text { range (\%) }\end{array}$ & $\begin{array}{l}\text { No. of healthy } \\
\text { individuals studied }\end{array}$ & Reference \\
\hline 0.04 & 3 & $43 \pm 26$ & $15-88$ & 12 & (82) \\
\hline 0.02 & 3 & $35 \pm 17$ & 17-59 & 6 & (82) \\
\hline 0.02 & 3 & $56 \pm 27$ & $0-100$ & 23 & (84) \\
\hline 0.01 & 3 & $46 \pm 20$ & $12-74$ & 20 & (86) \\
\hline 0.01 & 10 & $76 \pm 16$ & 37-96 & 13 & $(87)^{\star}$ \\
\hline 0.02 & 15 & $76 \pm 22$ & $32-98$ & 15 & (88) \\
\hline 0.02 & 15 & $57 \pm 29$ & 22-98 & 60 & (85) \\
\hline 0.01 & 30 & $64 \pm 20$ & 26-95 & 14 & (84) \\
\hline 0.02 & 30 & $70 \pm 22$ & 17-97 & 23 & (84) \\
\hline 0.02 & 30 & $71 \pm 25$ & 8-99 & 60 & (85) \\
\hline 0.015 & 45 & $75 \pm 12$ & $>40^{\dagger}$ & 40 & (3) \\
\hline 0.01 & 60 & $68 \pm 16$ & $15-88$ & 20 & (86) \\
\hline 0.02 & 60 & $84 \pm 16$ & $38-100$ & 60 & (85) \\
\hline
\end{tabular}

${ }^{\star}$ Subjects were prescreened with a 3-min sincalide stimulation, and those with GBEF < 35\% were excluded.

†95\% confidence limits. 
duct and excludes acute cholecystitis with a high degree of certainty. When patient preparation induces preferential bile flow to the gallbladder (such as in cases of sincalide pretreatment), activity in the small intestine may not be seen during the first hour (or even longer than $2 \mathrm{~h}$ ) in healthy individuals (91).

2. The hallmark of acute cholecystitis (acalculous as well as calculous) is persistent gallbladder nonvisualization after 3-4 h of passive imaging or $30 \mathrm{~min}$ after morphine administration. A pericholecystic hepatic band of increased activity (rim sign) is a sign of severe late-stage acute cholecystitis and has been associated with severe phlegmonous or gangrenous acute cholecystitis, a surgical emergency (92).

3. Chronic cholecystitis and clinical settings associated with physiologic failure of the gallbladder to fill with radiotracer (e.g., prolonged fasting for $>24-48 \mathrm{~h}$; severely ill or postoperative hospitalized patients) may result in gallbladder nonfilling within the first hour but may be distinguished from acute cholecystitis using lowdose intravenous morphine (see above) or delayed imaging. In chronic cholecystitis, the gallbladder will usually be seen within 30 min of morphine administration or on 3- to 4-h delayed images, whereas true cystic duct obstruction (acute cholecystitis) will result in persistent gallbladder nonvisualization. A gallbladder that is not visualized until after the time that the bowel is visualized correlates significantly with chronic cholecystitis.

4. A reduced GBEF in response to sincalide occurs in calculous and acalculous biliary diseases (i.e., chronic acalculous cholecystitis, cystic duct syndrome, sphincter of Oddi spasm) and may also be associated with various nonbiliary diseases and conditions and a variety of medications (e.g., morphine, atropine, calcium channel blockers, octreotide, progesterone, indomethacin, theophylline, benzodiazepines, and histamine-2 receptor antagonists).

5. Delayed biliary-to-bowel transit beyond $60 \mathrm{~min}$ raises suspicion of partial obstruction of the common bile duct, although this may be seen as a normal variant in up to $20 \%$ of individuals. With high-grade common bile duct obstruction, there is usually prompt liver uptake but no secretion of the radiotracer into biliary ducts. With prolonged obstruction, concomitant hepatic dysfunction may be seen. With partial biliary obstruction, radiotracer fills the biliary system but clears poorly proximal to the obstruction by $60 \mathrm{~min}$ or on delayed images at 2-4 $\mathrm{h}$ or with sincalide. Clearance into the bowel may or may not be seen. Severe hepatocellular dysfunction may also demonstrate delayed biliary-to-bowel transit.

6. A bile leak is present when tracer is found in a location other than the liver, gallbladder, bile ducts, bowel, or urine. Leakage may be seen more easily using a cinematic display or decubitus positioning, as described above.
7. Biliary atresia can be excluded scintigraphically by demonstrating transit of radiotracer into the bowel. Failure of tracer to enter the gut is consistent with biliary atresia but can also be caused by hepatocellular disease or immature intrahepatic transport mechanisms. Renal or urinary excretion of the tracer (especially in a diaper) may be confused with bowel activity and is a potential source of erroneous interpretation.

8. During a hepatobiliary scan, activity may reflux from the duodenum into the stomach. Bile reflux that is marked and occurs in a symptomatic patient correlates strongly with bile gastritis, a cause of epigastric discomfort.

9. After cholecystectomy, sphincter of Oddi dysfunction has the appearance of partial common bile duct obstruction. Pretreatment with sincalide or morphine may improve the sensitivity for its detection. Various visual, quantitative, and semiquantitative scintigraphic parameters of bile clearance have been used in conjunction with image analysis. (e.g., a scoring system, hepatic hilum-to-duodenum transit time, and percentage biliary emptying after morphine provocation).

\section{G. Sources of error}

1. The causes of a false-positive study (gallbladder nonvisualization in the absence of acute cholecystitis) include:

a. Insufficient fasting $(<2-4 \mathrm{~h})$

b. Prolonged fasting ( $>24 \mathrm{~h}$ ), especially total parenteral nutrition (despite sincalide pretreatment and morphine augmentation)

c. Severe hepatocellular disease

d. High-grade common bile duct obstruction

e. Severe intercurrent illness (despite sincalide pretreatment and morphine augmentation)

f. Pancreatitis (rare)

g. Rapid biliary-to-bowel transit (insufficient tracer activity remaining in the liver for delayed imaging)

h. Severe chronic cholecystitis

i. Previous cholecystectomy

2. The causes of a false-negative study (gallbladder visualization in the presence of acute cholecystitis) are rare but include:

a. A bowel loop simulating gallbladder (Drinking 100-200 mL water may remove the radiopharmaceutical from the duodenum and allow differentiation of gallbladder from bowel. Review of dynamic images in a cine display may also be helpful. A right lateral view should be obtained to better distinguish activity in the duodenum from that of the gallbladder.)

b. Acute acalculous cholecystitis

c. The presence of the dilated-cystic-duct sign simulating gallbladder (If this sign is present, morphine should not be given.)

d. A bile leak due to gallbladder perforation

e. Congenital anomalies simulating the gallbladder 
TABLE 2

Radiation Dosimetry in Adults

\begin{tabular}{|c|c|c|c|c|c|c|c|}
\hline \multirow[b]{2}{*}{ Radiopharmaceutical } & \multicolumn{2}{|c|}{ Administered activity } & \multicolumn{3}{|c|}{ Largest radiation dose } & \multicolumn{2}{|c|}{ Effective dose } \\
\hline & $\mathrm{MBq}$ & $\mathrm{mCi}$ & Organ & $\mathrm{mGy} / \mathrm{MBq}$ & $\mathrm{rad} / \mathrm{mCi}$ & $\mathrm{mSv} / \mathrm{MBq}$ & $\mathrm{rem} / \mathrm{mCi}$ \\
\hline 99mTc-disofenin or ${ }^{99 m T c-m e b r o f e n i n ~}$ & 56-180 intravenously & $1.5-5.0$ & Gallbladder wall & 0.11 & 0.41 & 0.017 & 0.063 \\
\hline${ }^{*}$ Data are from (95). & & & & & & & \\
\hline
\end{tabular}

TABLE 3

Radiation Dosimetry in Children

\begin{tabular}{|c|c|c|c|c|c|c|c|c|}
\hline \multirow[b]{2}{*}{ Radiopharmaceutical } & \multicolumn{2}{|c|}{ Administered activity } & \multirow[b]{2}{*}{ Age(y) } & \multicolumn{3}{|c|}{ Largest radiation dose } & \multicolumn{2}{|c|}{ Effective dose } \\
\hline & $\mathrm{MBq} / \mathrm{kg}$ & $\mathrm{mCi} / \mathrm{kg}$ & & Organ & mGy/MBq & $\mathrm{rad} / \mathrm{mCi}$ & $\overline{\mathrm{mSv} / \mathrm{MBq}}$ & $\mathrm{rem} / \mathrm{mCi}$ \\
\hline \multirow[t]{2}{*}{ 99mTc-disofenin } & 1.85 intravenously & 0.05 & 1 & Gallbladder wall & 0.95 & 3.5 & 0.10 & 0.37 \\
\hline & & & 5 & ULI & 0.29 & 1.1 & 0.045 & 0.17 \\
\hline \multirow[t]{2}{*}{ 99mTc-mebrofenin } & 1.85 intravenously & 0.05 & 10 & ULI & 0.18 & 0.67 & 0.029 & 0.11 \\
\hline & & & 15 & Gallbladder wall & 0.12 & 0.44 & 0.021 & 0.078 \\
\hline
\end{tabular}

*Data are from (95).

$\mathrm{ULI}=$ upper large intestine.

TABLE 4

Radiation Dosimetry in the Pregnant or Potentially Pregnant Patient

\begin{tabular}{lcc}
\hline & \multicolumn{2}{c}{ Fetal dose } \\
\cline { 2 - 3 } Stage of gestation & $\mathrm{mGy} / \mathrm{MBq}$ & $\mathrm{rad} / \mathrm{mCi}$ \\
\hline Early & 0.017 & 0.063 \\
$3 \mathrm{mo}$ & 0.015 & 0.056 \\
$6 \mathrm{mo}$ & 0.012 & 0.044 \\
$9 \mathrm{mo}$ & 0.0067 & 0.025
\end{tabular}

Dose estimates to fetus are from Russell et al. (96) and allow a physician to make the best possible informed recommendation to an individual patient. However, no information about possible placental crossover of hepatobiliary compounds is available.

f. Activity in the kidneys simulating the gallbladder or small bowel (may be clarified by a lateral image)

\section{DOCUMENTATION/REPORTING}

A. Goals of a report

See Section VII.A of the SNM Procedure Guideline for General Imaging.

B. Direct communication

See Section VII.B of the SNM Procedure Guideline for General Imaging.

C. Written communication

See section VII.C of the SNM Procedure Guideline for General Imaging.

D. Contents of the report

1. Study identification

2. Patient demographics
3. Clinical information (indication for the study; e.g., suspected acute cholecystitis, common bile duct obstruction, or a bile leak)

It is useful to include the patient's medications in this part of the historical review, especially the last dose of potentially interfering medications. The last oral food intake is also useful to record.

4. Comparison/correlative imaging data

5. Procedure description

a. Radiopharmaceutical and activity administered

b. Other medications given and their dosage (e.g., pretreatment with sincalide, morphine, or posttreatment with sincalide)

c. The duration of imaging and whether special or delayed views were obtained

6. Description of findings

Include the appearance of the liver, intrahepatic ducts, common bile duct, the presence and time of tracer appearance in the gallbladder or small bowel, any unusual activity (e.g., bile leak or enterogastric reflux), and any quantitative data generated (e.g., GBEF).

7. Study limitations (patient reactions to drugs administered)

If there is an allergic or other adverse reaction to the radiopharmaceutical or other administered pharmaceuticals, the reaction must be clearly stated in the findings and impression sections of the report. Gastrointestinal symptoms elicited by sincalide infusion are related to the rapid infusions and are not observed with the recommended slower infusion techniques of 45 and $60 \mathrm{~min}$. Gastrointestinal symptoms occurring during the shorter sincalide infusion have no specificity for gallbladder pathology (93) and should not be part of the study report. 


\section{Impression}

The impression should be concise and as precise as possible, should address the clinical question, should provide a differential diagnosis, and should make recommendations if appropriate. Any urgent or unexpected findings should be directly communicated to the referring physician, and this communication should be documented.

\section{EQUIPMENT SPECIFICATIONS}

A large-field-of-view $\gamma$-camera equipped with a low-energy all-purpose or high-resolution collimator is recommended. A SPECT or SPECT/CT camera may be used to detect the location of a biliary leak (38) or to estimate liver remnant function in patients preparing for partial hepatectomy (66).

\section{QUALITY CONTROL AND IMPROVEMENT, SAFETY, INFECTION CONTROL, AND PATIENT EDUCATION CONCERNS}

See Section IX of the SNM Procedure Guideline for General Imaging.

\section{RADIATION SAFETY IN IMAGING}

See Section X of the SNM Procedure Guideline for General Imaging for general guidance. Radiation dosimetry in adults, children, and pregnant or potentially pregnant patients is presented in Tables 2-4.

Administration of radiopharmaceuticals to the pregnant or potentially pregnant patient is addressed in the SNM Procedure Guideline for General Imaging. The physician must consider the indication for the test, the potential benefit of information it may provide toward improved care of the patient, and the potential risk it may pose to the fetus.

Administration of radiopharmaceuticals to the breastfeeding patient is addressed in the SNM Procedure Guideline for General Imaging. ICRP Publication 106, Appendix $\mathrm{D}$, recommends that lactating patients who receive ${ }^{99 \mathrm{~m}} \mathrm{Tc}-$ iminodiacetic acid compounds require no interruption of breastfeeding (94).

\section{ACKNOWLEDGMENTS}

The Committee on SNM Guidelines consists of the following individuals: Kevin J. Donohoe, MD (Chair) (Beth Israel Deaconess Medical Center, Boston, MA); Dominique Delbeke, MD (Vanderbilt University Medical Center, Nashville, TN); Twyla Bartel, DO (UAMS, Little Rock, AR); Paul E. Christian, CNMT, BS, PET (Huntsman Cancer Institute, University of Utah, Salt Lake City, UT); S. James Cullom, $\mathrm{PhD}$ (Cardiovascular Imaging Technology, Kansas City, MO); Lynnette A. Fulk, CNMT, FSNMTS (Clarian Health Methodist, Kokomo, IN); Ernest V. Garcia, PhD (Emory University Hospital, Atlanta, GA); Heather Jacene, MD (Johns Hopkins University, Baltimore, MD); David H. Lewis, MD (Harborview Medical Center, Seattle, WA); Josef Machac, MD (Mt. Sinai Hospital, Haworth, NY); J. Anthony Parker, MD, PhD
(Beth Israel Deaconess Medical Center, Boston, MA); Heiko Schoder, MD (Memorial Sloan-Kettering Cancer Center, New York, NY); Barry L. Shulkin, MD, MBA (St. Jude Children's Research Hospital, Memphis, TN); Arnol M. Takalkar, MD, MS (Biomedical Research Foundation Northwest Louisiana, Shreveport, LA); Alan D. Waxman, MD (Cedars-Sinai Medical Center, Los Angeles, CA); and Mark D. Wittry, MD (West County Radiological Group, Inc., St. Louis, MO).

\section{REFERENCES}

1. Pickleman J, Peiss RL, Henkin R, Salo B, Nagel P. The role of sincalide cholescintigraphy in the evaluation of patients with acalculus gallbladder disease. Arch Surg. 1985;120:693-697.

2. Fink-Bennett D, DeRidder P, Kolozsi WZ, Gordon R, Jaros R. Cholecystokinin cholescintigraphy: detection of abnormal gallbladder motor function in patients with chronic acalculous gallbladder disease. J Nucl Med. 1991;32:1695-1699.

3. Yap L, Wycherley AG, Morphett AD, Toouli J. Acalculous biliary pain: cholecystectomy alleviates symptoms in patients with abnormal cholescintigraphy. Gastroenterology. 1991;101:786-793.

4. Sorenson MK, Fancher S, Lang NP, Eidt JF, Broadwater JR. Abnormal gallbladder nuclear ejection fraction predicts success of cholecystectomy in patients with biliary dyskinesia. Am J Surg. 1993;166:672-674.

5. Watson A, Better N, Kalff V, Nottle P, Scelwyn M, Kelly MJ. Cholecystokinin (CCK)-HIDA scintigraphy in patients with suspected gall-bladder dysfunction. Australas Radiol. 1994;38:30-33.

6. Canfield AJ, Hetz SP, Schriver JP, et al. Biliary dyskinesia: a study of more than 200 patients and review of the literature. J Gastrointest Surg. 1998;2: 443-448.

7. Middleton GW, Williams JH. Diagnostic accuracy of 99Tcm-HIDA with cholecystokinin and gallbladder ejection fraction in acalculous gallbladder disease. Nucl Med Commun. 2001;22:657-661.

8. Poynter MT, Saba AK, Evans RA, Johnson WM, Hasl DM. Chronic acalculous biliary disease: cholecystokinin cholescintigraphy is useful in formulating treatment strategy and predicting success after cholecystectomy. Am Surg. 2002;68: 382-384.

9. Majeski J. Gallbladder ejection fraction: an accurate evaluation of symptomatic acalculous gallbladder disease. Int Surg. 2003;88:95-99.

10. Patel NA, Lamb JJ, Hogle NJ, Fowler DL. Therapeutic efficacy of laparoscopic cholecystectomy in the treatment of biliary dyskinesia. Am J Surg. 2004;187: 209-212.

11. Majd M, Shreve PD. Practice Guideline for the Performance of Adult and Pediatric Hepatobiliary Scintigraphy. Reston, VA: American College of Radiology; 2008:1-5.

12. Campbell BT, Narasimhan NP, Golladay ES, Hirschl RB. Biliary dyskinesia: a potentially unrecognized cause of abdominal pain in children. Pediatr Surg Int. 2004;20:579-581.

13. Constantinou C, Sucandy I, Ramenofsky M. Laparoscopic cholecystectomy for biliary dyskinesia in children: report of 100 cases from a single institution. Am Surg. 2008;74:587-592.

14. Haricharan RN, Proklova LV, Aprahamian CJ, et al. Laparoscopic cholecystectomy for biliary dyskinesia in children provides durable symptom relief. $\mathrm{JPe}$ diatr Surg. 2008;43:1060-1064.

15. Hofeldt M, Richmond B, Huffman K, Nestor J, Maxwell D. Laparoscopic cholecystectomy for treatment of biliary dyskinesia is safe and effective in the pediatric population. Am Surg. 2008;74:1069-1072.

16. Siddiqui S, Newbrough S, Alterman D, Anderson A, Kennedy A Jr. Efficacy of laparoscopic cholecystectomy in the pediatric population. J Pediatr Surg. 2008;43:109-113.

17. St Peter SD, Keckler SJ, Nair A, et al. Laparoscopic cholecystectomy in the pediatric population. J Laparoendosc Adv Surg Tech A. 2008;18:127-130.

18. Flancbaum L, Alden SM, Trooskin SZ. Use of cholescintigraphy with morphine in critically ill patients with suspected cholecystitis. Surgery. 1989;106:668-673.

19. Fig LM, Wahl RL, Stewart RE, Shapiro B. Morphine-augmented hepatobiliary scintigraphy in the severely ill: caution is in order. Radiology. 1990;175:467473.

20. Fink-Bennett D, Balon H, Robbins T, Tsai D. Morphine-augmented cholescintigraphy: its efficacy in detecting acute cholecystitis. J Nucl Med. 1991;32:12311233 .

21. Kim CK, Yun M, Lim JK, Lin X, Krynyckyi BR, Machac J. Refinement of the positive predictive value of gallbladder nonvisualization after morphine admin- 
istration for acute cholecystitis based on the temporal pattern of common bile duct activity. Clin Nucl Med. 2000;25:603-607.

22. Garner WL, Marx MV, Fabri PJ. Cholescintigraphy in the critically ill. Am J Surg. 1988;155:727-729.

23. Prevot N, Mariat G, Mahul P, et al. Contribution of cholescintigraphy to the early diagnosis of acute acalculous cholecystitis in intensive-care-unit patients. Eur J Nucl Med. 1999;26:1317-1325.

24. Pare P, Shaffer EA, Rosenthall L. Nonvisualization of the gallbladder by ${ }^{99 \mathrm{~m}} \mathrm{Tc}-$ HIDA cholescintigraphy as evidence of cholecystitis. Can Med Assoc J. 1978;118:384-386.

25. Kim CK, Tse KK, Juweid M, Mozley PD, Woda A, Alavi A. Cholescintigraphy in the diagnosis of acute cholecystitis: morphine augmentation is superior to delayed imaging. J Nucl Med. 1993;34:1866-1870.

26. Kim CK. Pharmacologic intervention for the diagnosis of acute cholecystitis: cholecystokinin pretreatment or morphine, or both? J Nucl Med. 1997;38:647-649.

27. Kim EE, Pjura G, Lowry P, Nguyen M, Pollack M. Morphine-augmented cholescintigraphy in the diagnosis of acute cholecystitis. AJR. 1986;147:11771179.

28. Kistler AM, Ziessman HA, Gooch D, Bitterman P. Morphine-augmented cholescintigraphy in acute cholecystitis: a satisfactory alternative to delayed imaging. Clin Nucl Med. 1991;16:404-406.

29. Chatziioannou SN, Moore WH, Ford PV, Dhekne RD. Hepatobiliary scintigraphy is superior to abdominal ultrasonography in suspected acute cholecystitis. Surgery. 2000;127:609-613.

30. Strasberg SM. Clinical practice: acute calculous cholecystitis. $N$ Engl J Med. 2008;358:2804-2811.

31. Bree LR, Rosen MP, Foley WD, et al. Right Upper Quadrant Pain: ACR Appropriateness Criteria. Reston, VA: American College of Radiology; 2007: $1-5$.

32. Floyd JL, Collins TL. Discordance of sonography and cholescintigraphy in acute biliary obstruction. AJR. 1983;140:501-502.

33. Noel AW, Velchik MG, Alavi A. The "liver scan" appearance in cholescintigraphy: a sign of complete common bile duct obstruction. Clin Nucl Med. 1985;10:264-269.

34. Lieberman DA, Krishnamurthy GT. Intrahepatic versus extrahepatic cholestasis: discrimination with biliary scintigraphy combined with ultrasound. Gastroenterology. 1986;90:734-743.

35. Kloiber R, AuCoin R, Hershfield NB, et al. Biliary obstruction after cholecystectomy: diagnosis with quantitative cholescintigraphy. Radiology. 1988;169: 643-647.

36. Nagle CE, Fink-Bennett D, Freitas JE. Bile ascites in adults: diagnosis using hepatobiliary scintigraphy and paracentesis. Clin Nucl Med. 1985;10:403-405.

37. Mochizuki T, Tauxe WN, Dobkin J, et al. Detection of complications after liver transplantation by technetium- $99 \mathrm{~m}$ mebrofenin hepatobiliary scintigraphy. Ann Nucl Med. 1991;5:103-107.

38. Tan KG, Bartholomeusz FD, Chatterton BE. Detection and follow up of biliary leak on Tc-99m DIDA SPECT-CT scans. Clin Nucl Med. 2004;29:642-643.

39. Fleming KW, Lucey BC, Soto JA, Oates ME. Posttraumatic bile leaks: role of diagnostic imaging and impact on patient outcome. Emerg Radiol. 2006;12:103107.

40. Dominguez EP, Giammar D, Baumert J, Ruiz O. A prospective study of bile leaks after laparoscopic cholecystectomy for acute cholecystitis. Am Surg. 2006;72:265-268.

41. Majd M, Reba RC, Altman RP. Hepatobiliary scintigraphy with ${ }^{99 \mathrm{~m} T c-P I P I D A}$ in the evaluation of neonatal jaundice. Pediatrics. 1981;67:140-145.

42. Sevilla A, Howman-Giles R, Saleh H, et al. Hepatobiliary scintigraphy with SPECT in infancy. Clin Nucl Med. 2007;32:16-23.

43. Poddar U, Bhattacharya A, Thapa BR, Mittal BR, Singh K. Ursodeoxycholic acid-augmented hepatobiliary scintigraphy in the evaluation of neonatal jaundice. J Nucl Med. 2004;45:1488-1492.

44. Rodeck B, Becker AC, Gratz KF, Petersen C. Early predictors of success of Kasai operation in children with biliary atresia. Eur J Pediatr Surg. 2007;17: 308-312.

45. Castagnetti M, Davenport M, Tizzard S, Hadzic N, Mieli-Vergani G, BuxtonThomas M. Hepatobiliary scintigraphy after Kasai procedure for biliary atresia: clinical correlation and prognostic value. J Pediatr Surg. 2007;42:1107-1113.

46. Gencoglu E, Karakayali H, Moray G, Aktas A, Haberal M. Evaluation of pediatric liver transplant recipients using quantitative hepatobiliary scintigraphy. Transplant Proc. 2002;34:2160-2162.

47. Gelfand MJ, Smith HS, Ryckman FC, et al. Hepatobiliary scintigraphy in pediatric liver transplant recipients. Clin Nucl Med. 1992;17:542-549.

48. Gencoglu EA, Karakayali H, Moray G, Haberal M. Comparison of graft function in heterotopic and orthotopic liver transplant recipients using hepatobiliary scintigraphy. Transplant Proc. 2002;34:2156-2158.
49. Lantsberg S, Lanchbury EE, Drolc ZA. Evaluation of bile duct complications after orthotopic liver transplantation by hepatobiliary scanning. Nucl Med Commun. 1990;11:761-769.

50. Shah AN, Dodson F, Fung J. Role of nuclear medicine in liver transplantation. Semin Nucl Med. 1995;25:36-48.

51. Aktas A, Koyuncu A, Dalgic A, Haberal M. Comparison of early postoperative function of liver and renal allografts with radionuclide imaging. Transplant Proc. 2005;37:355-358.

52. Muthukrishnan A, Shanthly N, Kumar S. Afferent loop syndrome: the role of Tc-99m mebrofenin hepatobiliary scintigraphy. Clin Nucl Med. 2000;25:492494.

53. Chandramouli B, Gupta SM. Scintigraphic detection of transient afferent loop obstruction. Clin Nucl Med. 1993;18:68-69.

54. Sivelli R, Farinon AM, Sianesi M, Percudani M, Ugolotti G, Calbiani B. Technetium-99m HIDA hepatobiliary scanning in evaluation of afferent loop syndrome. Am J Surg. 1984;148:262-265.

55. Rao K, Gooneratne N, Asokan S, Davis T, Nitekman M. Afferent loop obstruction documented with hepatobiliary imaging. Gastrointest Radiol. 1983;8:345347.

56. Rosenthall L, Fonseca C, Arzoumanian A, Hernandez M, Greenberg D. ${ }^{99 \mathrm{~m} T c-}$ IDA hepatobiliary imaging following upper abdominal surgery. Radiology. 1979;130:735-739.

57. Camponovo E, Buck JL, Drane WE. Scintigraphic features of choledochal cyst. J Nucl Med. 1989;30:622-628.

58. Papanicolaou N, Abramson SJ, Teele RL, Treves S. Specific preoperative diagnosis of choledochal cysts by combined sonography and hepatobiliary scintigraphy. Ann Radiol (Paris). 1985;28:276-282.

59. Huang MJ, Liaw YF. Intravenous cholescintigraphy using Tc-99m-labeled agents in the diagnosis of choledochal cyst. J Nucl Med. 1982;23:113-116.

60. Kao PF, Huang MJ, Tzen KY, You DL, Liaw YF. The clinical significance of gall-bladder non-visualization in cholescintigraphy of patients with choledochal cysts. Eur J Nucl Med. 1996;23:1468-1472.

61. Mettler FA Jr, Wicks JD, Requard CK, Christie JH. Diagnostic imaging of choledochal cysts. Clin Nucl Med. 1981;6:513-518.

62. Miller TT, Palestro CJ, Groisman GM, Norton KI, Dolgin S. Choledochal cyst: preoperative sonographic and scintigraphic assessment. Clin Nucl Med. 1993;18: 1001-1002.

63. Paramsothy M, Somasundram K. Technetium 99m-diethyl-IDA hepatobiliary scintigraphy in the pre-operative diagnosis of choledochal cyst. $\mathrm{Br} J$ Radiol. 1981;54:1104-1107.

64. Tuncel M, Ergun EL. Value of hepatobiliary scintigraphy after type 1 choledochal cyst excision and Roux-en-Y hepatojejunostomy. Clin Nucl Med. 2006;31: 93-95.

65. Dinant S, de Graaf W, Verwer BJ, et al. Risk assessment of posthepatectomy liver failure using hepatobiliary scintigraphy and CT volumetry. $\mathrm{J} \mathrm{Nucl} \mathrm{Med}$. 2007;48:685-692.

66. de Graaf W, van Lienden KP, van Gulik TM, Bennink RJ. ${ }^{99 m}$ Tc-mebrofenin hepatobiliary scintigraphy with SPECT for the assessment of hepatic function and liver functional volume before partial hepatectomy. J Nucl Med. 2010;51:229-236

67. Arakawa K, Hoshi H, Jinnouchi S, et al. Hepatic anomalous lobulation demonstrated by liver and hepatobiliary scintigraphy. Clin Nucl Med. 1984;9: $565-567$.

68. Drane WE, Karvelis K, Johnson DA, Silverman ED. Scintigraphic evaluation of duodenogastric reflux: problems, pitfalls, and technical review. Clin Nucl Med. 1987;12:377-384.

69. Caravel JP, Bonaz B, Hostein J, Bost R, Fournet J. Scintigraphic study of gallbladder emptying and duodenogastric reflux during non-ulcerous dyspepsia. Eur J Nucl Med. 1990;17:134-141.

70. Piergiuseppe O, Francesco G, Luigi M. Evaluation of biliary enterogastric reflux with Tc-99m HIDA in partial situs inversus. Clin Nucl Med. 1997; 22:657-659.

71. Arroyo AJ, Burns JB, Huyghe WA, Dollman AE, Patel YP. Enterogastric reflux mimicking gallbladder disease: detection, quantitation and potential significance. J Nucl Med Technol. 1999;27:207-214.

72. Adachi S, Takeda T, Fukao K. Evaluation of esophageal bile reflux after total gastrectomy by gastrointestinal and hepatobiliary dual scintigraphy. Surg Today. 1999;29:301-306.

73. Sostre S, Kalloo AN, Spiegler EJ, Camargo EE, Wagner HN Jr. A noninvasive test of sphincter of Oddi dysfunction in postcholecystectomy patients: the scintigraphic score. J Nucl Med. 1992;33:1216-1222.

74. Corazziari E, Cicala M, Habib FI, et al. Hepatoduodenal bile transit in cholecystectomized subjects: relationship with sphincter of Oddi function and diagnostic value. Dig Dis Sci. 1994;39:1985-1993. 
75. Thomas PD, Turner JG, Dobbs BR, Burt MJ, Chapman BA. Use of ${ }^{99 m}$ Tc-DISIDA biliary scanning with morphine provocation for the detection of elevated sphincter of Oddi basal pressure. Gut. 2000;46:838-841.

76. Rosenblatt ML, Catalano MF, Alcocer E, Geenen JE. Comparison of sphincter of Oddi manometry, fatty meal sonography, and hepatobiliary scintigraphy in the diagnosis of sphincter of Oddi dysfunction. Gastrointest Endosc. 2001;54:697-704.

77. Cicala M, Habib FI, Vavassori P, et al. Outcome of endoscopic sphincterotomy in post cholecystectomy patients with sphincter of Oddi dysfunction as predicted by manometry and quantitative choledochoscintigraphy. Gut. 2002;50: 665-668.

78. Kinevac: Sincalide for Injection [package insert]. Princeton, NJ: Bracco Diagnostics Inc.; 2004.

79. SNM Web site. North American Consensus Guidelines for Administered Radiopharmaceutical Activities in Children and Adolescents. Available at: http://www. snm.org/docs/pediatric_dose_consensus_guidelines_final_2010.pdf. Accessed October $8,2010$.

80. Brown PH, Juni JE, Lieberman DA, Krishnamurthy GT. Hepatocyte versus biliary disease: a distinction by deconvolutional analysis of technetium-99m IDA time-activity curves. J Nucl Med. 1988;29:623-630.

81. Juni JE, Reichle R. Measurement of hepatocellular function with deconvolutional analysis: application in the differential diagnosis of acute jaundice. Radiology. 1990; 177:171-175.

82. Mesgarzadeh M, Krishnamurthy GT, Bobba VR, Langrell K. Filling, postcholecystokinin emptying, and refilling of normal gallbladder: effects of two different doses of CCK on refilling: concise communication. J Nucl Med. 1983;24: 666-671.

83. Patterson FK, Kam JW. Practical hepatobiliary imaging using pretreatment with sincalide in 139 hepatobiliary studies. Clin Nucl Med. 1985;10:333-335.

84. Ziessman HA, Fahey FH, Hixson DJ. Calculation of a gallbladder ejection fraction: advantage of continuous sincalide infusion over the three-minute infusion method. J Nucl Med. 1992;33:537-541.

85. Ziessman HA, Tulchinsky M, Lavely WC, et al. Sincalide-stimulated cholescintigraphy: a multicenter investigation to determine optimal infusion methodology and gallbladder ejection fraction normal values. J Nucl Med. 2010; $51: 277-281$.
86. Ziessman HA, Muenz LR, Agarwal AK. ZaZa AA. Normal values for sincalide cholescintigraphy: comparison of two methods. Radiology. 2001;221:404-410.

87. Krishnamurthy GT, Brown PH. Comparison of fatty meal and intravenous cholecystokinin infusion for gallbladder ejection fraction. J Nucl Med. 2002;43: 1603-1610.

88. Raymond F, Lepanto L, Rosenthall L, Fried GM. Tc-99m-IDA gallbladder kinetics and response to CCK in chronic cholecystitis. Eur J Nucl Med. 1988;14: 378-381.

89. Mackie CR, Baxter JN, Grime JS, Hulks G, Cuschieri A. Gall bladder emptying in normal subjects: a data base for clinical cholescintigraphy. Gut. 1987;28: 137-141.

90. Ziessman HA, Jones DA, Muenz LR, Agarval AK. Cholecystokinin cholescintigraphy: methodology and normal values using a lactose-free fatty-meal food supplement. J Nucl Med. 2003;44:1263-1266.

91. Kim CK, Palestro CJ, Solomon RW, Molinari DS, Lee SO, Goldsmith SJ. Delayed biliary-to-bowel transit in cholescintigraphy after cholecystokinin treatment. Radiology. 1990;176:553-556.

92. Meekin GK, Ziessman HA, Klappenbach RS. Prognostic value and pathophysiologic significance of the rim sign in cholescintigraphy. J Nucl Med. 1987;28: 1679-1682.

93. Smythe A, Majeed AW, Fitzhenry M, Johnson AG. A requiem for the cholecystokinin provocation test? Gut. 1998;43:571-574.

94. ICRP Publication 106: Radiation dose to patients from radiopharmaceuticals-a third amendment to ICRP publication 53. Ann ICRP. 2008;38:1-198.

95. ICRP Publication 80: Radiation dose to patients from radiopharmaceuticalsaddendum 2 to ICRP publication 53. Ann ICRP. 1998;28:1-126.

96. Russell JR, Stabin MG, Sparks RB, Watson E. Radiation absorbed dose to the embryo/fetus from radiopharmaceuticals. Health Phys. 1997;73:756-769.

\section{APPROVAL}

This Practice Guideline was approved by the Board of Directors of the SNM on June 4, 2010. 